\title{
Research on Post Office Class Curriculum Reform of Actual Combat in NCO Academies
}

\author{
Zhou Zelong $^{1, a}$, Liu Zhongmin ${ }^{2, b}$, Li Xingyin ${ }^{3, c}$ \\ 1Wuhan Mechanical College, Wuhan, 430075, China \\ ${ }^{\mathrm{a}}$ email, ${ }^{\mathrm{b}}$ email, ${ }^{\mathrm{c}}$ email,
}

Keywords: Actual combat, Post, Course Content

\begin{abstract}
The post office is at the core position in the course of curriculum system of sergeant education. Under the conditions of combat equipment maintenance support task for NCO academies post office class combat teaching put forward new and higher requirements, this paper on post office class curriculum content of combat reform were research and discussion..
\end{abstract}

\section{Analysis of Equipment Support Officer Post Office Class Status}

Post class curriculum is a combination of theory and practice closely, it is the core course of training students post ability. The purpose of the setting is to train the students' post office ability, so the post class course must focus on the post, strengthen the ability. For the protection of the Cadet equipment, through the post office in the course of learning, master professional skills of equipment maintenance support theoretical knowledge and equipment inspection and maintenance methods, for the Corps of cadets served in weapons and equipment maintenance and support work to lay a good foundation. With new weapons and equipment will continue to install the base combat troops, the new main battle equipment and equipment fault mechanism and equipment fault detection and removal method has gradually changed, and part of the curriculum setting did not timely troops and equipment to install actual situation of adjusting the contents of courses set to, resulting in curriculum content in accordance with the traditional equipment maintenance support set, out of touch with the actual troops and equipment maintenance support, students graduated from colleges and universities still have to new equipment and technology training to posts, the posts class curriculum to sell at a discount greatly, the hysteresis of NCO cadets in the equipment maintenance support generation speed.

Equipment development with each passing day, the maintenance system reform of the curtain has been opened, the new maintenance and security system gradually built, and more reasonable. Equipment maintenance support tasks gradually sinking, more inclined to the grassroots. The traditional "put a screw blade sweep the world" individual maintenance form has been unable to adapt to the requirements of new maintenance tasks, especially for the maintenance of new complex weapon platform system appeared to be inadequate. New equipment often set machine, electricity, liquid, light technology in one, single maintenance support form is incapable of real conditions of some types of equipment maintenance support mission requirements, the conditions of combat team collaborative maintenance, battlefield repair training courses is the future equipment maintenance guarantee way. For the harsh environment of the battlefield in the future, harsh repair requirements have been unable to work in accordance with the current position of the class course content in general repair processes and methods for maintenance.

Post office class curriculum not only to make the students in the classroom, specializing in indoor through learning and training master operation of equipment use, maintenance methods, understand the structure principle and learn the basic fault detection and maintenance method, and the need to in the setting of curriculum content considered reflecting the actual characteristics, in 
line with the actual situation. The equipment support Cadet post office class curriculum based on peacetime maintenance mode, the purpose is mainly to ensure equipment good state of combat readiness and use in training and other operations. However, the main purpose is to ensure the maintenance of equipment by the high repetition rate and the ratio of the war, in order to maintain the fighting capacity of the army. The performance and maintenance of the content of the equipment different combat environment will change, at the same time for the equipment fault repair policy clock also with the usual maintenance be quite different. Under the condition of actual combat, the army has a long distance maneuver. In the unfamiliar area environment, the maintenance method of equipment maintenance and the failure mechanism and the maintenance mode are very different. Post class courses and actual combat environment in line with the degree of the students can make use of the knowledge formed in accordance with the actual conditions of the maintenance of the requirements of the post office capacity.

\section{Post Office Equipment Support Officer Courses Combat Reform}

Firstly, Post office courses to be consistent with the army main battle equipment training content. "Close to the equipment teaching" is close to the main equipment, and the future battlefield equipment support actual consistency. In the setting of curriculum content increased new main battle equipment and equipment fault mechanism and equipment fault detection and elimination of in line with the requirements of the practical teaching content. On the curriculum content system to rational allocation of traditional equipment and new equipment course setting proportion, increase research efforts, to find out the main battle equipment teaching content demand, strengthen overall planning, gradually reduce the non combat equipment course content, post office class courses targeted, at the same time to add new equipment inspection and maintenance method and equipment operation course, aimed at the real battle equipment support teaching to carry out, make the equipment support NCO cadets after college post office courses, to master the troops of the corresponding types of main battle equipment support skills, achieve graduation to posts.

Secondly, Post office class curriculum settings in addition to make teaching equipment type and actual combat is consistent, also need to make the curriculum content and the main battle equipment under the conditions of combat equipment maintenance support mode consistent. On the basis of the actual combat conditions, the team cooperation training should be gradually increased to the post class course. The team cooperative maintenance is an important form of the future battlefield large-scale complex platform weapon system and the routine equipment maintenance support. In the post office class curriculum, should be to force the actual equipment maintenance work flow is according to add maintenance teams and groups of subjects related to the content, according to the working process of the system of teaching the typical team synergy maintenance support subjects into classroom teaching, so that the team collaborative maintenance training course content to implement the specific types of equipment, specific positions, specific equipment technical support ability, the team cooperation and enrich the post office class curriculum. At the same time, considering the actual conditions the same types of claims equipment routine maintenance and wartime maintenance difference, battlefield emergency repair subjects should also into equipment security officer posts class course content. Battlefield repair subjects to according to the security needs of the equipment under combat conditions set, battlefield situation is constantly changing, may encounter the equipment fault form variety, only a reasonable summary of actual combat conditions under different types of main battle equipment fault case, to make combat environment of the battlefield repair process and fault elimination method, change the previous post office class course content based on the idea of "peacetime" flat ", the curriculum content" to fight ", truly 
achieve the post office class course content and combat environment maintenance to protect the contents of highly consistent.

Thirdly, Post office class course content aimed at actual combat must "peacetime and in war", "war" must combine the content of the course and the battlefield, with specific positions combined. Different combat geographical environments and different weather for the maintenance of the same type of equipment produced different effects, such as southern jungle and the northwest desert beach area to change garments according to the maintenance of equipment, the use of oil and the concrete implementation method of are vary greatly, LLL night conditions or field under adverse weather equipment maintenance support and specialized room carry out equipment maintenance training difficulty is much greater. In order to make the Cadet adapt to the requirements of the specific positions under different operation environment of equipment support tasks and post class course content according to the corresponding positions in the typical combat environment maintenance support process, increase under the different geographical environment main battle equipment maintenance operation training goal, including seasonal maintenance, daily oil use, equipped with dust and sand prevention method of waterproofing, cooling fluid examination increase injection, and the gun in different areas of driving before training, artillery fire after technical examination combat training courses. Equipment which is suitable for all-weather operations must also be included in the training content of equipment support subjects under the condition of the rainy season, dry season and low light level night vision. Adverse weather conditions, equipment support training courses to focus on a simulated combat environment, set the students use specific maintenance method and equipment etc., including waterproof and dustproof device method, LLL night training equipment and under harsh conditions to carry out equipment maintenance support with process.

\section{Post Office Equipment Support Officer Class Curriculum Reform Practice Combat Strategy}

Firstly, for a new weapon system column loaded troops for a short period of time, the factory with dispensing data lack and future operations can not be separated from the reality of the new main battle equipment. On the basis of extensive research, scientific and reasonable to the post class curriculum content optimization and integration.

In increasing part and the force model of equipment type security content consistent with the post office class course content at the same time, through reasonable optimization hours, adjust the part of the traditional equipment course content, the deletion of the actual combat conditions, do not use or less use of service subjects, merger and reorganization of the Ministry of content before and after the overlapping of curriculum content.

Secondly, under the conditions of combat team synergy maintenance training courses has gradually become the basic form of equipment maintenance support in wartime, in individual maintenance training courses based on post office class curriculum is necessary increase under the conditions of actual team synergy maintenance subjects. According to the actual typical army maintenance team maintenance training subjects are summarized, according to different groups, cross training form, both to ensure the maintenance team within each officers to "specialize in" effect, namely the specific equipment type a part or a module can be responsible for maintenance, ensure when encountered maintenance tasks quickly and accurately, and cross training attrition alternative subject training, the maintenance team within each Cadet name in addition to the maintenance module to make their own business skills, we must master the other modules in the maintenance task team maintenance tasks or maintenance procedures and methods, in order to ensure combat in combat. The other officers can replenish the alternative, complete the 
corresponding maintenance tasks. The battlefield repair training subjects included in the post office class course content must apply". According to the military exercises and the Red Army against the actual equipment maintenance support process, set up the battlefield repair subjects, subject content covers the March maneuver, shooting in front of the various aspects of the fault detection and exclusion. More subjects in training at the same time, professional skills contest is introduced to the post office class curriculum. By setting the individual maintenance subject contest and maintenance teams and groups subjects contest and battlefield repair subject contest, inviting grass-roots unit maintenance experts as judges referee, guide their professional skills contest in the post office class curriculum.

Thirdly, Aiming at the influence of different operational area environment and different weather on the equipment support form, the course content of the post class has increased the equipment maintenance support subject training based on different terrain and weather condition. After the completion of the construction principles of curriculum, according to the area of operations and the weather characteristics set the corresponding equipment support training subjects, especially for night natural weak light environment subjects of night training organization to carry out exploration and practice.

\section{Conclusion}

By in the post office class curriculum content increased for different combat regional environment and different weather equipment support training courses, the course content is more close to actual combat, to carry out night training subjects and battle damage assessment subjects, and enhance the post office class teaching content of the effectiveness and pertinence.

\section{References}

[1] Li Ying, Su Ying, Zhao Weikang. Close to the actual teaching, strengthen faculty construction, science guide [J], 2015 (12)

[2] Ma Zhisong, Niu Tao, Yu Hong. The army combat combat course teaching reform of continuing education, [J], 2013 (11)

[3] He LiQiu. The actual teaching to enhance students' competency research, [J] Journal of Hubei University of Police, 2014 (6) 